\title{
NRAS NP_002515.1:p.G12C
}

National Cancer Institute

\section{Source}

National Cancer Institute. NRAS NP 002515.1:p.G12C. NCI Thesaurus. Code C155669.

A change in the amino acid residue at position 12 in the GT Pase NRas protein where

glycine has been replaced by cysteine. 